\title{
Effect of chronic fish oil supplementation on renal function of normal and cachectic rats
}

\section{R. Fernandez ${ }^{1}$, J. Piechnik ${ }^{1}$, R. Fabris ${ }^{1}$, G. Malnic ${ }^{2}$ and L.C. Fernandes ${ }^{1}$}

\author{
'Departamento de Fisiologia, Setor de Ciências Biológicas, \\ Universidade Federal do Paraná, Curitiba, PR, Brasil \\ ${ }^{2}$ Departamento de Fisiologia e Biofísica, Instituto de Ciências Biomédicas, \\ Universidade de São Paulo, São Paulo, SP, Brasil
}

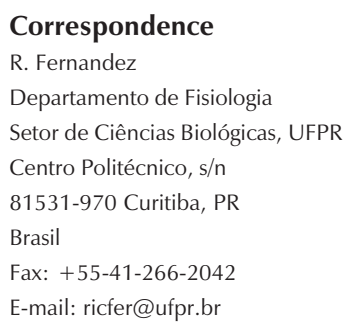

Received February 27, 2004 Accepted June 24, 2004

\begin{abstract}
In the present study we determined the effect of chronic diet supplementation with n-3 PUFA on renal function of healthy and cachectic subjects by providing fish oil ( $1 \mathrm{~g} / \mathrm{kg}$ body weight) to female rats throughout pregnancy and lactation and then to their offspring postweaning and examined its effect on renal function parameters during their adulthood. The animals were divided into four groups of 5-10 rats in each group: control, control supplemented with fish oil (P), cachectic Walker 256 tumor-bearing (W), and W supplemented with fish oil (WP). Food intake was significantly lower in the W group compared to control $(12.66 \pm 4.24$ vs $25.30 \pm 1.07 \mathrm{~g} /$ day $)$. Treatment with fish oil significantly reversed this reduction $(22.70 \pm 2.94 \mathrm{~g} /$ day $)$. Tumor growth rate was markedly reduced in the P group (16.41 \pm 2.09 for WP vs $24.06 \pm 2.64 \mathrm{~g}$ for $\mathrm{W}$ ). WP group showed a significant increase in mean glomerular filtration rate compared to $\mathrm{P}$ and control $\left(1.520 \pm 0.214 \mathrm{ml} \mathrm{min}^{-1} \mathrm{~kg}\right.$ body weight $\left.{ }^{-1} ; \mathrm{P}<0.05\right)$. Tumor-bearing groups had low urine osmolality compared to control rats. The fractional sodium excretion decreased in the $\mathrm{W}$ group compared to control $(0.43 \pm 0.16$ vs $2.99 \pm 0.87 \% ; \mathrm{P}<0.05)$, and partially recovered in the WP group $(0.90 \pm 0.20 \%)$. In summary, the chronic supplementation with fish oil used in this study increased the amount of fat in the diet by only $0.1 \%$, but caused remarkable changes in tumor growth rate and cachexia, also showing a renoprotective function.
\end{abstract}

\section{Introduction}

After ingestion, linoleic and alpha linolenic acids are desaturated and elongated to produce the $n-3$ and $n-6$ polyunsaturated fatty acid (PUFA) families, respectively. The principal members of the n-3 PUFA family are eicosapentaenoic acid (EPA) and docosahexaenoic acid (DHA), whereas arachidonic
Key words

- Fish oil supplementation

- Renal function

- Cachexia

- Walker 256 tumor

- Sodium excretion

- Glomerular filtration rate 
epoxyeicosatrienoic acids, eicosatetraenoic acids and monooxygenated AA derivatives (2). The cyclooxygenase enzyme system is the major pathway for AA in the kidney and these products modulate the action of the other hormones or autacoids, in particular their physiologic actions on renal vascular tone, mesangial and glomerular functions and the handling of salt and water (2). Inhibition of cyclooxygenase activity in the absence of exogenous administration or endogenous release of hormones such as angiotensin II or arginine-vasopressin has little effect on renal functional parameters $(3,4)$. However, the products of cyclooxygenase metabolism have been implicated in the mediation of renal function changes observed in several disorders: glomerular injury (IgA nephropathy, lupus nephritis, etc.), various forms of acute and chronic renal failure, allograft rejection, cyclosporine nephrotoxicity, hepatorenal syndrome, diabetic nephropathy, and renal hypertension (5-7).

Fish oil diets rich in n-3 PUFA should result in competition by these substrates for AA oxygenation pathways, resulting in the formation of biologically inactive end products $(1,8)$. This mechanism explains the beneficial effect of fish oil diets on the course of the diseases cited above (9-11). The effect of diet supplementation with n-3 PUFA on renal function parameters of healthy subjects has been less studied. Dusing et al. (12) supplemented 10 healthy adult volunteers with 6 g/day n-3 PUFA for 6 weeks and observed a significant increment of renal plasma flow and glomerular filtration rate (GFR), associated with a decrease in renal vascular resistance. Other investigators supplemented elderly persons with $1.7 \mathrm{~g} /$ day EPA for 4 weeks and did not observe any modification of renal function (13). On the other hand, chronic supplementation of normal rats for more than 6 months resulted in a reduction of GFR and proteinuria $(14,15)$. These deleterious effects were associated with evidence of increased renal lipid per- oxidation (15). In all of these studies the supplementation was administered to adult subjects.

Over the past 150 years, human beings have enormously increased the consumption of saturated and n-6 PUFAs and reduced the consumption of n-3 PUFAs (16). This typical Western diet has been found to exert a stimulatory effect on the growth of cancer cell lines (17). Epidemiologic and experimental studies have shown that long-chain n-3 PUFAs have the ability to chemoprevent and chemosuppress tumor growth (18-20), but the underlying mechanism is unknown. The cachexia syndrome develops in association with tumor growth, contributing to physical disability and mortality. It is characterized by anorexia, weight loss, early satiety, changes in taste perception, weakness, anemia and edema, depletion of carbohydrate, protein and lipid stores, and skeletal muscle wasting (21). The incidence of cancer cachexia varies widely. In fact, $20-70 \%$ of cancer patients die with cachexia as the primary cause, depending upon the type of tumor (22). The basic mechanisms responsible for the establishment of cancer cachexia are poorly known. Impaired salt-water excretion is a well-known systemic effect of cancer cachexia, and has been studied in several animal models including Walker 256 tumor-bearing rats (23). In association with these alterations in water-electrolyte metabolism, some forms of carcinomas involve glomerular disease, manifested mainly as heavy proteinuria or progressive renal failure (24).

Most previous studies investigating the effect of dietary fatty acids on tumor growth in laboratory animals have used young adult animals fed for a short period before or after induction of the tumor. A more likely scenario is that a dietary pattern will be lifelong and may exist from conception. We are not aware of any studies that have investigated the effect of lifelong consumption of particular fatty acids on water-electrolyte metabolism and renal function of cachectic animals. 
In the present study we provided fish oil (rich in n-3 PUFA) to female rats throughout pregnancy and lactation and then to their offspring post-weaning and examined its effect on renal function parameters of the offspring during their adulthood. The offspring were divided into two groups: healthy subjects and Walker 256 tumor-bearing rats.

\section{Material and Methods}

\section{Study design and tumor inoculation}

The study was approved by the local Animal Ethics Committee. Wistar rats were obtained from the Setor de Ciências Biológicas, UFPR, and maintained in the animal house under controlled temperature $\left(23^{\circ} \mathrm{C}\right)$, humidity and a 12-h light-dark cycle, with free access to water and standard commercial chow (Nurilab CR1, Nuvital Nutrients Ltda., Curitiba, PR, Brazil), containing 117 $\mathrm{mmol} / \mathrm{kg}$ sodium and $273 \mathrm{mmol} / \mathrm{kg}$ potassium.

Weanling female Wistar rats (aged 21 days) were divided into two groups. One received a normal chow diet ad libitum (control rats), while the other was orally supplemented with fish oil-n-3 PUFA (MaxEpa; Seven Seas, Hull, UK). The fish oil used was a mixed marine triacylglycerol preparation containing $180 \mathrm{~g}$ EPA and $120 \mathrm{~g}$ DHA per $\mathrm{kg}$. The fish oil supplement was administered at a dose of $1 \mathrm{~g} / \mathrm{kg}$ body weight per day and was given orally as a single bolus using a precision microliter pipette. At the age of 90 days, the rats were mated with male Wistar rats which had been fed a normal laboratory chow. The females continued to receive fatty acid supplementation throughout gestation and lactation. After weaning (age 21 days) the male offspring received the same diet and supplementation as their mothers.

At 90 days of age half the animals of each group were injected into the right flank with a sterile suspension of $2 \times 10^{7}$ Walker 256 tumor cells obtained from an ascitic tumor- bearing rat, and the other animals were injected with $1.0 \mathrm{ml} 0.9 \%(\mathrm{w} / \mathrm{v}) \mathrm{NaCl}$ without anesthesia, as previously described (25). The amount injected ensured that the tumor mass was $8-10 \%$ of the carcass weight at the time of the measurements (the 14th day after inoculation). The following groups were set up with 5-10 rats in each: control, control rats supplemented with fish oil-n-3 PUFA (P), Walker 256 tumor-bearing rats (W), and Walker 256 tumor-bearing rats supplemented with fish oil (WP). Body weight was determined every two days for 14 days.

\section{Kidney function}

The rats were prepared for kidney function measurements as follows. All animals were housed individually in metabolic cages for 6 days prior to sacrifice. The cages were equipped with external food cups and water bottles that facilitated accurate collection of urine not contaminated with feces or food. Metabolic balance was determined during the experimental period by measurement of body weight (g), food consumption (g), water ingestion $(\mathrm{ml})$, urinary volume $(\mathrm{ml})$, and $\mathrm{Na}^{+}$concentration $(\mathrm{mEq} / \mathrm{l})$. GFR and urine concentrating capacity were determined by measuring creatinine and osmolar clearance, respectively, on the 14th day after tumor inoculation, when the animals were killed by decapitation without anesthesia using a guillotine. The tumor was removed and weighed. Blood was collected and serum creatinine and $\mathrm{Na}^{+}$concentrations, total protein content, and osmolality were determined. Fractional sodium excretion $\left(\mathrm{FE}_{\mathrm{Na}^{+}}\right)$was calculated as $\mathrm{C}_{\mathrm{Na}^{+}} / \mathrm{C}_{\mathrm{Cr}}$, where $\mathrm{C}_{\mathrm{Na}^{+}}$is Na ion clearance and $\mathrm{C}_{\mathrm{Cr}}$ is creatinine clearance. Fractional sodium balance was calculated as sodium intake minus urinary sodium losses divided by sodium intake. Sodium intake was calculated from the amount of diet ingested per $24 \mathrm{~h}$, and sodium losses were estimated from the amount of sodium excreted into the urine within the same $24 \mathrm{~h}$. 


\section{Blood and urine measurements}

$\mathrm{Na}^{+}$concentration in plasma and urine was measured by flame photometry (Micronal B262, São Paulo, SP, Brazil). Osmolality of blood and urine was measured by freezing point depression with a Fiske OM Osmometer (Norwood, MA, USA). Plasma and urine creatinine was measured by a colorimetric method (picric acid) and total blood and urine protein content was determined by the biuret method (Labtest Diagnostica, Lagoa Santa, MG, Brazil).

\section{Statistical analysis}

Data are reported as means \pm SEM. Statistical comparisons were made by analysis of variance (ANOVA) followed by the Stu-

Table 1. Effect of chronic fish oil supplementation on daily food consumption, water ingestion, weight gain, and urinary volume of the groups studied.

\begin{tabular}{lllcc}
\hline & $C(N=10)$ & $P(N=9)$ & $W(N=6)$ & $W P(N=8)$ \\
\hline Food consumption (g/day) & $25.3 \pm 1.07$ & $24.7 \pm 1.88$ & $12.66 \pm 4.24^{*}$ & $22.7 \pm 2.94$ \\
Water ingestion (ml/day) & $39.0 \pm 2.3$ & $34.7 \pm 2.2$ & $37.2 \pm 7.4$ & $39.7 \pm 2.6$ \\
Weight gain (\%/day) & $1.18 \pm 0.56$ & $1.05 \pm 0.79$ & $0.44 \pm 1.62^{*}$ & $1.78 \pm 1.30^{*}$ \\
& & & $(-8.96 \pm 2.68)$ & $(-7.02 \pm 1.67)$ \\
Urine volume (ml/day) & $5.3 \pm 1.4$ & $4.6 \pm 0.7$ & $3.2 \pm 1.4$ & $8.8 \pm 1.3^{+}$ \\
\hline
\end{tabular}

$C=$ control; $P=$ control supplemented with fish oil; $W=$ Walker 256 tumor-bearing rats $(W) ; W P=$ Walker 256 tumor-bearing rats supplemented with fish oil. Data are reported as mean \pm SEM. The values in parentheses represent the percentage of weight gain calculated considering only the carcass weight.

${ }^{*} P<0.05$ vs control group. ${ }^{+} P<0.05$ vs the other groups (ANOVA, followed by the Student-Newman-Keuls contrast test).

Figure 1. Fish oil supplementation increases glomerular filtration rate (GFR) in rats. GFR is reported as $\mathrm{ml} \mathrm{min}^{-1} \mathrm{~kg}$ body weight ${ }^{-1}$ estimated by creatinine clearance for control rats $(\mathrm{C}, \mathrm{N}=$ 7), control rats supplemented with fish oil-n-3 PUFA (P, N = 10), Walker 256 tumor-bearing rats $(W, N=5)$, and $W$ supplemented with fish oil rats (WP, N $=8$ ). Data are reported as means \pm SEM. Note that the WP group

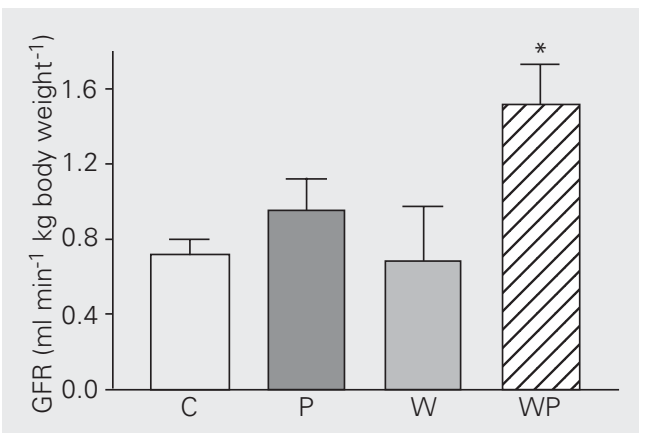

has a significant increment of GFR compared to the other groups $(P<0.05$, ANOVA, followed by the Student-Newman-Keuls contrast test).
dent-Newman-Keuls contrast test and the level of significance was set at $\mathrm{P}<0.05$.

\section{Results}

The average daily weight gain of the different groups is shown in Table 1. The body weight gain of the $\mathrm{P}$ group was similar to the control group, but for the $\mathrm{W}$ group it was less than control $(0.44 \pm 1.62$ vs $1.18 \pm$ $0.56 \%, \mathrm{P}<0.05)$. A tendency to body weight gain was observed in the WP group but the gain was not significant when compared to the other groups (Table 1). However, if only the carcass weight (body weight on the 14th day minus tumor weight) of the W and WP groups is considered, the daily weight gain was significantly less than in the other groups $(-8.96 \pm 2.68$ in W and $-7.02 \pm 1.67 \%$ in WP; Table 1). Food intake by the $\mathrm{W}$ group was significantly lower than control (12.66 \pm 4.24 vs $25.30 \pm 1.07 \mathrm{~g} /$ day, $\mathrm{P}<0.05$; Table 1). Treatment with fish oil significantly reversed the reduction of food intake observed in the $\mathrm{W}$ group $(22.70 \pm 2.94$ vs $12.66 \pm 4.24$ $\mathrm{g} /$ day, $\mathrm{P}<0.05$; Table 1). Water ingestion did not differ between groups. The tumor growth rate was markedly reduced in the $\mathrm{P}$ group compared to the untreated one (16.41 \pm 2.09 for WP vs $24.06 \pm 2.64 \mathrm{~g}$ for $\mathrm{W}, \mathrm{P}<$ $0.05)$. The tumor-bearing groups presented clear signs of cancer cachexia, i.e., a depletion of protein stores. The total plasma protein concentration in the tumor-bearing groups was $3.84 \pm 0.23$ in $\mathrm{W}$ and $3.91 \pm 0.21$ $\mathrm{g} / \mathrm{dl}$ in WP, significantly different from the control and P groups: $4.72 \pm 0.20$ and $4.74 \pm$ $0.17 \mathrm{~g} / \mathrm{dl}$, respectively.

Renal function is depicted in Figure 1, which shows GFR estimated by creatinine clearance. Mean GFR showed a tendency to increase in the $\mathrm{P}$ group, but was not significantly different from the control group $(0.935$ $\pm 0.167(\mathrm{~N}=10)$ vs $0.719 \pm 0.084 \mathrm{ml} \mathrm{min}^{-1}$ $\mathrm{kg}$ body weight $\left.{ }^{-1}(\mathrm{~N}=7), \mathrm{P}>0.05\right)$. In the $\mathrm{W}$ group, GFR was statistically similar to the control and P groups, $0.684 \pm 0.289 \mathrm{ml} \mathrm{min}^{-1}$ 
$\mathrm{kg}$ body weight ${ }^{-1}(\mathrm{~N}=5)$. At the same time, the WP group showed a significant increase in GFR: $1.520 \pm 0.214 \mathrm{ml} \mathrm{min}^{-1} \mathrm{~kg}$ body weight $^{-1}(\mathrm{~N}=8)(\mathrm{P}<0.05)$ vs the other groups. This group had also an elevated urine flow rate: $8.8 \pm 1.3$ vs $5.3 \pm 0.72 \mathrm{ml} /$ day in the control group, $\mathrm{P}<0.05$ (Table 1). Despite the differences observed in GFR, plasma creatinine concentration was similar among groups: $20.21 \pm 1.20$ in control $(\mathrm{N}=$ 7), $20.23 \pm 2.32$ in $\mathrm{P}(\mathrm{N}=10), 19.40 \pm 1.84$ in $\mathrm{W}(\mathrm{N}=5)$, and $17.00 \pm 1.22 \mu \mathrm{g} / \mathrm{ml}$ in $\mathrm{WP}$ $(\mathrm{N}=8)$.

The tumor-bearing groups had low urine osmolality compared to control rats, but only $\mathrm{W}$ rats showed a significant alteration of osmolar clearance (Table 2). Despite these differences, plasma osmolality was similar among the different groups (see Table 2). Figure 2 shows renal $\mathrm{FE}_{\mathrm{Na}^{+}}$. The $\mathrm{FE}_{\mathrm{Na}^{+}}$of $\mathrm{P}$ rats was similar to control, $2.29 \pm 0.92$ and $2.99 \pm 0.87 \%$, respectively $(\mathrm{P}>0.05)$. In contrast, $\mathrm{FE}_{\mathrm{Na}}+$ was decreased in the $\mathrm{W}$ group compared to control: $0.43 \pm 0.16$ vs $2.99 \pm$ $0.87 \%, \mathrm{P}<0.05$. Urinary sodium excretion partially recovered in the WP group to $0.90 \pm$ $0.20 \%$, but this value was not statistically different from the $\mathrm{W}$ group. There were no significant difference between groups for fractional sodium balance $(0.66 \pm 0.02$ in control, $0.64 \pm 0.11$ in $\mathrm{P}, 0.85 \pm 0.07$ in $\mathrm{W}$, and $0.63 \pm 0.09 \%$ in WP). Despite the significant reduction of renal $\mathrm{FE}_{\mathrm{Na}^{2}}$ observed in the $\mathrm{W}$ group, plasma sodium concentration was similar to the control group: $143.2 \pm 3.8$ and $142.4 \pm 3.1 \mathrm{mEq} / \mathrm{l}$, respectively. The plasma sodium concentration of the other groups was also similar to control: $137.1 \pm$ 1.83 in $\mathrm{P}$, and $137.8 \pm 3.06 \mathrm{mEq} / \mathrm{l}$ in WP.

\section{Discussion}

The lower prevalence of coronary heart disease and of some chronic diseases like psoriasis, bronchial asthma, diabetes, and thyrotoxicosis observed in Eskimo populations (Greenland Inuit) as compared to west- ern populations has been attributed to the increased supply of n-3 fatty acids (marine fish and mammals) in the former (26). Over the past 15 years, several studies have suggested the efficacy and potential clinical utility of dietary supplementation with n-3 fatty acids in human renal diseases such as idiopathic immunoglobulin A nephropathy, lupus nephritis, cyclosporine A toxicity, vascular access thrombosis of end-stage renal disease, idiopathic calcium urolithiasis, and chronic renal insufficiency $(10,27-29)$. The most accepted hypothesis to explain the multifaceted actions of n-3 fatty acids on kidney diseases concerns the activities of metabolites derived from EPA as opposed to those derived from AA. Alterations in eicosanoid synthesis and metabolism are produced when concentrations of EPA and DHA increase relative to AA. For example, renal produc-

Table 2. Effect of chronic fish oil supplementation on plasma osmolalily (Posm), urine osmolality (UOSM), osmolar clearance $\left(\mathrm{C}_{\mathrm{OSM}}\right)$, and free water clearance $\left(\mathrm{C}_{\mathrm{H}_{2} \mathrm{O}}\right)$ of the groups studied.

\begin{tabular}{lcccc}
\hline & $\begin{array}{c}\text { POSM } \\
(\mathrm{mOsm} /)\end{array}$ & $\begin{array}{c}\text { UOSM } \\
(\mathrm{mOsm} /)\end{array}$ & $\begin{array}{c}\mathrm{C} \text { OSM } \\
(\mathrm{ml} / \mathrm{min})\end{array}$ & $\begin{array}{c}\mathrm{C}_{\mathrm{H}_{2} \mathrm{O}} \\
(\mathrm{ml} / \mathrm{min})\end{array}$ \\
\hline $\mathrm{C}(\mathrm{N}=7)$ & $286 \pm 5.3$ & $2719 \pm 348$ & $0.035 \pm 0.005$ & $-0.030 \pm 0.005$ \\
$\mathrm{P}(\mathrm{N}=5)$ & $279 \pm 4.5$ & $2265 \pm 441$ & $0.028 \pm 0.008$ & $-0.021 \pm 0.009$ \\
$W(\mathrm{~N}=5)$ & $291 \pm 9.5$ & $1245 \pm 238^{*}$ & $0.016 \pm 0.007^{*}$ & $-0.023 \pm 0.012$ \\
$W P(\mathrm{~N}=8)$ & $285 \pm 2.4$ & $1594 \pm 260^{*}$ & $0.039 \pm 0.006$ & $-0.030 \pm 0.005$
\end{tabular}

$\mathrm{C}=$ control; $\mathrm{P}=$ control supplemented with fish oil; $\mathrm{W}=$ Walker 256 tumor-bearing rats; $W P=$ Walker 256 tumor-bearing rats supplemented with fish oil. Data are reported as mean \pm SEM.

${ }^{*} \mathrm{P}<0.05$ vs control group (ANOVA, followed by the Student-Newman-Keuls contrast test).

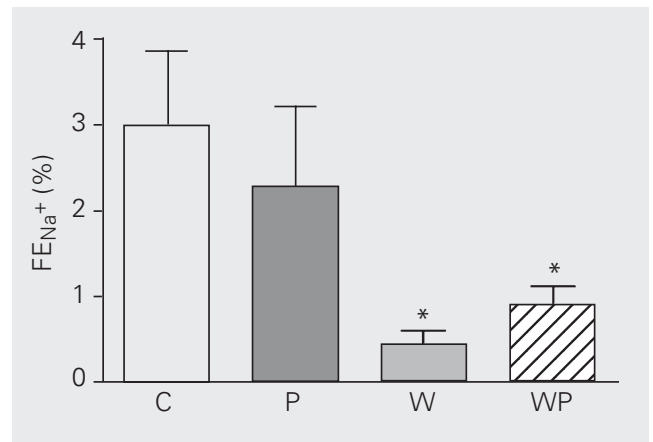

Figure 2. Fractional sodium excretion $\left(\mathrm{FE}_{\mathrm{Na}^{+}}{ }^{+}\right.$) of control rats $(C, N=7)$, control rats supplemented with fish oil-n-3 PUFA $(P, N=5)$, Walker 256 tumorbearing rats $(\mathrm{W}, \mathrm{N}=5)$, and $\mathrm{W}$ supplemented with fish oil rats (WP, N = 8). Data are reported as means \pm SEM. Note that the $W$ group has a significant decrease in $\mathrm{FE}_{\mathrm{Na}^{+}}$compared to control $(\mathrm{P}<0.05$, ANOVA, followed by the Student-NewmanKeuls contrast test). 
tion of thromboxane $\mathrm{A}_{2}\left(\mathrm{TXA}_{2}\right)$ is elevated in several renal diseases and the treatment with n-3 fatty acids reduced it.

Despite the numerous studies on several renal diseases, few investigations have examined the effects of dietary supplementation with n-3 fatty acids on renal function of healthy animals. In the present study we observed that chronic dietary supplementation with n-3 fatty acids (0.3 g EPA and DHA $/ \mathrm{kg}$ body weight per day) did not alter significantly the GFR (see Figure 1), urine flow rate (see Table 1) or $\mathrm{FE}_{\mathrm{Na}}{ }^{+}$(see Figure 2). Similarly, Logan et al. (15) observed that feeding fish oil to rats for 1 month had no effect on mean GFR (determined by inulin clearance) or renal plasma flow. However, Schmitz et al. (30) observed a significant increase in single nephron GFR when glomerular hemodynamics was evaluated by micropuncture in rats. The elevation of single nephron GFR was primarily due to a marked increase in single nephron plasma flow, which was associated with a significant reduction in efferent arteriolar resistance. The discrepancies observed between studies could be attributed to differences in the experimental design, such as duration of the supplementation period, and amount of fish oil in the diet. The cited study (30) was performed after 4 to 6 weeks of dietary n-3 fatty acid supplementation, and ours after 15-17 weeks. In addition, Schmitz et al. (30) fed their animals a standard laboratory chow supplemented with $18 \%$ (w/w) fish oil (approximately $0.8 \mathrm{~g} \mathrm{n}-3 /$ day), and we fed ours less than $1 \%$ (approximately $0.07 \mathrm{~g} \mathrm{n}-3 /$ day).

Fish oil supplementation accelerates the natural age-induced decline in glomerular function. More than six months of dietary fish oil had a deleterious effect on kidney function, evidenced by diminished glomerular filtration and increased urinary protein excretion $(14,15)$. This effect is inconsistent with a previous study that found no adverse impact with 16 months' feeding of fish oil versus safflower oil on serum creatinine lev- els, urinary protein excretion or renal morphology in female Wistar rats (31).

Cachexia-anorexia syndrome is a common manifestation of cancer and of nonmalignant chronic diseases, such as AIDS, advanced congestive heart failure, chronic obstructive pulmonary disease, and rheumatoid arthritis, among others (32). Thus, success in managing the syndrome would help cancer patients and people with other common illnesses. A presumably successful attack on cancer cachexia syndrome should focus on agents able to increase food intake and reduce or inhibit intermediary metabolism. Epidemiological studies have shown a link between fat-rich diets and incidence of cancer (33). A reduced risk of colon, breast and prostate cancer has been associated with a low fat diet high in n-3 fatty acids, otherwise, the polyunsaturated $n-6$ exert a stimulatory effect on cancer development $(17,34)$.

In the current study tumor growth was associated with reduced food intake and animal growth, and reduced total serum protein concentration (see Table 1). Thus, this model induced cancer cachexia. Treatment with fish oil significantly reversed the reduction of food intake observed in the $\mathrm{W}$ rats, and reduced tumor growth rate. In a previous study by our group, we observed that several "cachectic" serum parameters such as glucose, lactate, cholesterol, and HDL-C returned to normal levels in WP rats (25). The mechanisms by which n-3 PUFAs combat neoplasmic cells are still unclear. Modifications in prostaglandin biosynthesis, cyclooxygenase- 2 activity, angiogenesis, modulation of immune function, and lipid peroxidation have been suggested to play a role (35). The lytic effects of n-3 PUFA on cultured tumor cells are correlated with the degree of lipid peroxidation product formation. The mechanism(s) by which these lipid peroxidation products inhibit cancer cell growth is unknown (36).

During growth of Walker 256 carcinoma in control rats, water intake is sustained de- 
spite the progressive decline in food intake (Table 1). This apparently excessive water intake has been attributed to retention of water associated with the known retention of $\mathrm{Na}^{+}$under the influence of the increased secretion of aldosterone, and/or inappropriate antidiuretic hormone secretion $(23,37)$. Another factor to be considered is the decrease of total serum protein concentration, which causes a reduction in the colloid oncotic pressure in blood, favoring movement of water from the vascular to the interstitial space and producing hypovolemia. Hypovolemia would then activate volume sensors and extrarenal neurohumoral and hemodynamic mechanisms that increase renin-angiotensin-aldosterone, arginine-vasopressin, and sympathetic nervous system activity, and decrease atrial natriuretic peptide, which in turn would signal to the kidney to retain salt and water. However, the total daily solute load of urine in the tumor-bearing groups was relatively much lower than urine water excretion and so the urine became progressively more diluted (Table 2 ). Other investigators have reported a decrease in urinary $\mathrm{Na}^{+}$excretion of $\mathrm{W}$ rats, as observed in the present study $(38,39)$.

Associated with the decrease in urinary $\mathrm{Na}^{+}$excretion we observed a tendency toward sodium retention, expressed by a nonsignificant increment of sodium fractional balance. A clear relationship between tumor growth and sodium retention was established by Toal et al. (38), who observed a prompt return to normal urinary $\mathrm{Na}^{+}$excretion after tumor extirpation. Supplementation with fish oil attenuated the changes in renal fractional excretion and sodium balance determined by tumor growth (see Figure 2). It also determined a significant increment of GFR, clearly different from the W group (see Figure 1). The specific mechanisms responsible for this effect were not addressed in the present study; however, alterations of intrarenal vascular resistance and/or whole blood viscosity could be suggested. The n-3 PUFAs present in fish oil
(DHA and EPA) enhance the renal production and excretion of the trienoic series of eicosanoids: $\mathrm{PGI}_{3}, \mathrm{PGE}_{3}$ and $\mathrm{TXA}_{3}(12,27) . \mathrm{PGI}_{3}$, and $\mathrm{PGE}_{3}$ are potent renal vasodilators, whereas $\mathrm{TXA}_{3}$ has little effect on vascular smooth muscle tone. Moreover, production of the dienoic prostaglandins $\left(\mathrm{PGI}_{2}, \mathrm{PGE}_{2}\right)$ and the potent vasoconstrictor $\mathrm{TXA}_{2}$ is reduced by dietary supplementation with fish oil (27). Rats bearing the Walker 256 tumor have high circulating levels of the vasoconstrictor $\mathrm{PGE}_{2}$ compared with normal rats (40). As a consequence, the increment of GFR observed in the WP group could be explained by a reduction of intrarenal arteriolar resistance. Reduction in serum lipid levels is a factor that reduces whole blood viscosity. In a previous study, we observed that WP rats had a reduced serum triacylglycerol level as compared to the $\mathrm{W}$ group, but similar to control rats (41). Thus, dietary fish supplementation may have caused a reduction in plasma and/or whole blood viscosity that contributed to the decrease in renal vascular resistance. On the other hand, the control rats supplemented with fish oil had serum triacylglycerol and cholesterol levels similar to control animals (25). So, the lack of effect of this supplementation on renal function of control animals observed in the present study should be explained in part by the constancy of plasma lipid levels and in part by the little effect of inhibition of cyclooxygenase products on the renal parameters of normal rats and humans $(3,4)$.

The supplementation with fish oil used in this study increased the amount of fat in the diet by only $0.1 \%$. Thus, this approach is quite different from those used in other studies in which the diets were supplemented with percentages of n-3 PUFA ranging from 8 to $21 \%$. In addition, we also examined the effect of chronic supplementation on the F1 generation. Interestingly, this small change in n-3 PUFA intake caused remarkable changes in tumor growth rate and cachexia, also showing a renoprotective function. 


\section{References}

1. Lands WEM (1992). Biochemistry and physiology of n-3 fatty acids. FASEB Journal, 6: 2530-2536.

2. Mattix HJ \& Badr KF (2001). Arachidonic acid metabolites and the kidney. In: Brener BM (Editor), The Kidney. Chapter 18. 6th edn. WB Saunders, Philadelphia, PA USA, 765-794.

3. Zipser RD (1985). Effects of selective inhibition of thromboxane synthesis on renal function in humans. American Journal of Physiology, 248 (Part 2): F753-F756.

4. Munger K \& Baylis C (1988). Sex differences in renal hemodynamics in rats. American Journal of Physiology, 254 (Part 2): F223-F231.

5. Takahashi K, Schreiner GF, Yamashita K, Christman BW, Blair I \& Badr KF (1990). Predominant functional roles for thromboxane A2 and prostaglandin E2 during late nephrotoxic serum glomerulonephritis in the rat. Journal of Clinical Investigation, 85: 1974-1982.

6. Forpomes O, Combe C, Cambar J \& Aparicio M (1997). CyclosporinA- and angiotensin-II-induced vasoreactivity in isolated glomeruli and cultured mesangial cells, 4 and $24 \mathrm{~h}$ after renal mass reduction: role of vasodilatory prostaglandins. Nephron, 76: 337-344.

7. DeRubertis FR \& Craven PA (1993). Eicosanoids in the pathogenesis of the functional and structural alterations of the kidney in diabetes. American Journal of Kidney Diseases, 22: 727-735.

8. Culp BR, Titus BG \& Lands WE (1979). Inhibition of prostaglandin biosynthesis by eicosapentaenoic acid. Prostaglandins and Medicine, 3: 269-278.

9. Badalamenti S \& Salerno F (1995). Renal effects of dietary supplementation with fish oil in cyclosporine-treated liver transplant recipients. Hepatology, 22: 1695-1701.

10. Donadio JV (2001). n-3 Fatty acids and their role in nephrologic practice. Current Opinion in Nephrology and Hypertension, 10: 639642.

11. Brown SA, Brown CA, Crowell WA, Barsanti JA, Kang CW, Allen T, Cowell C \& Finco DR (2000). Effects of dietary polyunsaturated fatty acid supplementation in early renal insufficiency in dogs. Journal of Laboratory and Clinical Medicine, 135: 275-286.

12. Dusing R, Struck A, Gobel BO, Weiser B \& Vetter H (1990). Effects of $n-3$ fatty acids on renal function and renal prostaglandin $E$ metabolism. Kidney International, 38: 315-319.

13. Adam O, Schubert A, Adam A, Antretter N \& Forth W (1998). Effects of omega-3 fatty acids on renal function and electrolyte excretion in aged persons. European Journal of Medical Research, 3: 111-118.

14. Valente Gamba C, Zeraib Caraviello A, Matsushita A, Alves G, Nunes da Silva L, Nascimento Gomez G \& Zaladek Gil F (2001). Effects of dietary lipids on renal function of aged rats. Brazilian Journal of Medical and Biological Research, 34: 265-269.

15. Logan JL, Michael UF \& Benson B (1992). Dietary fish oil interferes with renal arachidonic acid metabolism in rats: correlations with renal physiology. Metabolism, 41: 382-389.

16. Simopoulos AP (1999). Essential fatty acids in health and chronic disease. American Journal of Clinical Nutrition, 70: 560S-569S.

17. Pandalai PK, Pilat MJ \& Yamazaki K (1996). The effects of omega-3 and omega- 6 fatty acids on in vitro prostate cancer growth. Anticancer Research, 16: 815-820.

18. Sauer LA, Dauchy RT \& Blask DE (2001). Polyunsaturated fatty acids, melatonin, and cancer prevention. Biochemical Pharmacology, 61: 1455-1461.

19. Rose DP \& Connolly JM (1999). Omega-3 fatty acids as cancer chemopreventive agents. Pharmacology and Therapeutics, 83: 217220.
20. Helton WS \& Espat NJ (2001). Defining mechanisms of $\omega-3$ fattyacid activity. Nutrition, 17: 674-680.

21. Tessitore L, Costelli LP \& Baccino FM (1994). Pharmacological interference with tissue hypercatabolism in tumor-bearing rats. Biochemical Journal, 299: 71-78.

22. Strassmann G, Fong M, Kenney JS \& Jacob CO (1992). Evidence for the involvement of interleukin-6 in experimental cancer cachexia. Journal of Clinical Investigation, 89: 1681-1684.

23. Blackburn GL, Maini BS, Bistrian BR \& McDermott Jr WV (1977) The effect of cancer on nitrogen, electrolyte and mineral metabolism. Cancer Research, 37: 2348-2353.

24. Usalan C \& Emry S (1998). Membranoproliferative glomerulonephritis associated with small cell lung carcinoma. International Urology and Nephrology, 30: 209-213.

25. Togni V, Ota C, Folador A et al. (2003). Cancer cachexia and tumor growth reduction in Walker 256 tumor-bearing rats supplemented with $\mathrm{n}-3$ polyunsaturated fatty acids for one generation. Nutrition and Cancer, 46: 52-58.

26. Bang HO, Dyerberg J \& Sinclair HM (1980). The composition of the Eskimo food in north western Greenland. American Journal of Clinical Nutrition, 33: 2657-2661.

27. De Caterina R, Endres S, Kristesen S \& Schmidt E (1994). n-3 Fatty acids and renal diseases. American Journal of Kidney Diseases, 24 397-415.

28. Baggio B, Budakovic A, Priante G, Gambaro G, Manzato E \& Khan S (2002). Dietary fatty acid supplementation modulates the urinary excretion of calcium and oxalate in the rat. Insight into calcium lithogenesis. Nephron, 91: 486-491.

29. Azar R, Dequiedt F, Awada J, Dequiedt P \& Tacquet A (1989). Effects of fish oil rich in polyunsaturated fatty acids on hyperlipidemia of hemodialysis patients. Kidney International, 27: S239S242.

30. Schmitz PG, O'Donnell MP, Kasiske BL \& Keane WF (1991). Glomerular hemodynamic effects of dietary polyunsaturated fatty acid supplementation. Journal of Laboratory and Clinical Medicine, 18: 129-135.

31. Barcelli UO, Beach DC \& Pollak VE (1988). The influence of $n-6$ and n-3 fatty acids on kidney phospholipid composition and on eicosanoid production in aging rats. Lipids, 23: 309-312.

32. Barber MD (2001). Cancer cachexia and its treatment with fish-oilenriched nutritional supplementation. Nutrition, 17: 751-755.

33. Caygill CPJ, Charlett A \& Hill MJ (1996). Fat, fish oil and cancer British Journal of Cancer, 74: 159-164.

34. Aronson WJ, Glaspy JA, Reddy ST, Reese D, Heber D \& Bagga D (2001). Modulation of omega-3/omega-6 polyunsaturated ratios with dietary fish oils in men with prostate cancer. Urology, 58: 283-288.

35. Jiang WG, Bryce RP \& Horrobin DF (1998). Essential fatty acids: molecular and cellular basis of their anti-cancer action and clinical implications. Critical Reviews in Oncology and Hematology, 27: 179-209.

36. Begin ME, Ells G \& Horrobin DF (1988). Polyunsaturated fatty acidinduced cytotoxicity against tumor cells and its relationship to lipid peroxidation. Journal of the National Cancer Institute, 80: 188-194.

37. Morrison SD (1971). Water intake and exchange and hydration of rats during growth of Walker 256 carcinoma. Journal of the National Cancer Institute, 46: 825-830.

38. Toal JN, Millar FK, Brooks RH \& White J (1961). Sodium retention by rats bearing the Walker carcinosarcoma 256. American Journal of 
Physiology, 200: 175-181.

39. Rettori O, Vieira-Matos AN \& Gontijo JAR (2000). Re-assessment of the renal hydrosaline dysfunction in rats bearing the Walker-256 tumor. Renal Failure, 22: 769-784.

40. Siddiqui RA \& Williams JF (1990). Tentative identification of the toxohormones of cancer cachexia: roles of vasopressin, prostaglandin E2 and cachectin-TNF. Biochemistry International, 20: 787-797.
41. Pinto Jr J, Bonato S, Aikawa J, Yamazaki R, Pizato N, Folador A, Facin M, Grohs H, Naliwaiko K, Ferraz AC, Nishiyama A, Fernandez R, Curi R \& Fernandes LC (2004). Fish oil supplementation in F1 generation associated to naproxen, clenbuterol and insulin administration reduce tumor growth and cachexia in Walker 256 tumorbearing rats. Journal of Nutritional Biochemistry, 15: 358-365. 